\title{
Diversified Transformation of University Inside and in Interaction with Industrial and Social Environment
}

\author{
Evgeniy Bryndin \\ Research Center "Estestvoinformatika", Novosibirsk, Russia
}

Email address:

bryndin15@yandex.ru

\section{To cite this article:}

Evgeniy Bryndin. Diversified Transformation of University Inside and in Interaction with Industrial and Social Environment. Education Journal. Vol. 9, No. 4, 2020, pp. 95-98. doi: 10.11648/j.edu.20200904.11

Received: May 31, 2020; Accepted: June 11, 2020; Published: June 23, 2020

\begin{abstract}
The main task of the higher educational institution is to ensure accumulation of up-to-date modern knowledge, competences and training experience, as well as development of skills and results of objective research of entities of phenomena, processes, objects and patterns of the real world and cultivation of multi-inter-disciplinary fundamental and applied researchers in priority areas of scientific technological development and strategically important industries. The university 's digital transformation should provide continuous learning, improve the learning ecosystem to train competent personnel with financial, legal, digital, entrepreneurial and professional literacy and systemic, creative, innovative and strategic thinking. This requires the involvement of broad stakeholder groups in the development and expansion of transformational mobility tools for university education. Transformational mobility of universities serves as a tool to increase the efficiency of university management, increase the quality of education and ensure its maximum individualization to the needs of a specific study and employer. The main principles of the construction of modern organizations, enterprises and institutions of innovative knowledge economy are the following: the principle of training through the solution of tasks the development of the system of regular participation of students and employees in the joint implementation of real projects within the framework of the activities of virtual project-oriented teams on orders of enterprises of domestic and world industry on the basis of the advanced acquisition and application of modern key competences, in the first and computer engineering technologies. The approach to determining the content of training involves the development of a system of core tasks that define the main directions for the development of science and technology in the relevant industry.
\end{abstract}

Keywords: Trans-disciplinary Research, Individual Learning, University Transformation, Knowledge Management Mobility

\section{Introduction}

The principle of learning mobility is realized by filling and changing the educational process in accordance with the needs of the students themselves. The principle of mobility of training makes it possible to respond flexibly to changes in the needs of individual companies and federation entities. This principle is manifested through the constant transformation of functional and organizational structures, allowing universities to adapt to training in rapidly changing technologies of innovation industry and industry.

The principle of mobility itself is manifested in the variety of means, methods, organizational forms of the system at all levels of education, their flexibility and readiness for rapid transformation in accordance with the changing needs of the individual, the labour market and society. It allows the use of different productive methodological systems and technologies, and consists in the creation of information networks, knowledge bases and data banks for remote education, as a result of which the student can adjust or supplement his educational program in the desired direction.

Various information and communication technologies are used to effectively ensure the principle of mobility, which provide flexible and fast interaction between all participants of the educational process [1].

At the level of vocational education, the teacher tracks the completion of internships and practices, educational programs, thus creating a system for effective monitoring of the mobility of students. The principle of mobility in vocational education is aimed at the formation of social, 
professional, communicative and other competences. These competencies contribute to the development of cognitive and socio-professional mobility of students of vocational education, which in turn are one of the priority qualities of a modern specialist. It involves constantly updating the content of training and improving knowledge, skills and skills as needed, in response to changes in the labour market.

The principle of mobility implies a continuous, advanced, capacity for accelerated and expanded training. Pupils learn to make rational decisions, in case of correction of professional activity in labor market, for obtaining missing knowledge, abilities, skills and ways of development of necessary competences and professions and to study several specialties in parallel with the right of obtaining diplomas in each of them.

Application of mobile principle in the system of state higher education allows to train qualified socially and professionally mobile specialists at the level of professional training, which is one of the most important priorities at the current stage of digital industrialization of society.

University education mobility is based on multi-crossdisciplinary fundamental and applied learning and research with verified diversified systemic mastery of competitive professional competencies.

\section{Multi-disciplinary Training and Cross-disciplinary Research}

Multi-disciplinary training is a combination of different disciplines with no clear links in content. Inter-disciplinary research is carried out on the basis of the knowledge and skills of two or more different disciplines, which can range from the simple exchange of ideas to the mutual integration of concepts and methodologies to understand, justify and possibly manage the phenomena of ultra-complex systems. Inter-disciplinary means collaboration within two or more scientific disciplines. The basic, initial form of inter-disciplinary is multidisciplinary, which involves quite free interaction of scientists from different disciplines, which is not aimed at formulating a common approach or obtaining collective results. On the contrary, advanced inter-disciplinary research aims to overcome the methodological and theoretical (including categorical) identities of the scientific disciplines involved in order to create a new, common conceptual framework and to produce innovative results. It is with inter-disciplinary research that the successes of modern natural sciences are connected. An inter-disciplinary approach is best suited to the study of complex, multilevel, heterogeneous, continuously changing institutional systems.

Trans - Disciplinary study aims to create a common system of axioms for a certain set of disciplines and integrate disciplinary paradigm for joint study and unity of knowledge. Trans - disciplinary is understood as a study of the subject (more precisely, elements of the subject area) of one scientific discipline using the methods and terminology of another discipline; In other words, it is the study of the subject of another by the representatives of one discipline.

The integration of educational and scientific activities, their synergy is a factor and a real means of increasing the efficiency and competitiveness of innovative high-tech activities. Synergy between education and science is a prerequisite for the development of an innovative economy.

Synergy between science and education provides an accelerated educational effect in the training of highly qualified researchers. The accelerated process of training highly qualified researchers is implemented by integrating higher education with advanced research fundamental science. Education and science, especially in their synergistic synthesis, are increasingly becoming the engine of technological progress, without which socio-economic progress is unthinkable in modern times. Qualitative training of researchers of higher qualification, based on alliance with scientific activity, is a priority of policy in all developed countries of the world, as well as a necessary component of the institutional structure of the innovation economy.

The reproduction of highly qualified researchers who meet the requirements of an innovative economy has a high priority. Large corporations should invest sufficient funds in research and development in the field of high technologies, training of specialists of appropriate quantity and quality, and form a system of public-private partnership in the field of higher education. The creation of large training complexes based on joint activities of the university and the production sector is one of the most important areas of intersectoral cooperation for the development of the high-tech industry.

The future is for researchers capable of constant creative self-realization. Albert Einstein said, "imagination is more important than knowledge." Development of creative abilities of a person, expansion of opportunities of individual research innovation activity, mobilization of potential of researcher for realization of own ideas and developments ensures mobility of creative innovative higher vocational education. The feature of such education is that it is aimed at developing a constant need for creation, search for a new one, accumulation of intellectual potential and its use in practice.

There is a new quality of work - creative activity as a function of self-realization of a holistic person, a personcreator. Deep basic training and mobility, characteristic of creative innovative higher vocational education, gives a synergistic effect, promotes continuous training, allows to predict and assess trends of development. Such education expands the perception of problems and solutions, stimulates creativity in solving them. But the main thing - implements the idea of necessity and possibility of training creative research activity. Now we need researchers with a search mentality, creative intuition, a clear vision of what a new technology should lead to.

Today creative innovative higher professional education and science, their synergy - the main resource of innovation activity and high-tech economy [2-12]. 


\section{Capitalization of Knowledge}

Awareness of knowledge as a commodity and an essential resource for the development of civilization, rapid development of the Internet, means of mobile communication and digital technologies, which provide opportunities for effective use of intellectual resources - all this determines fundamentally new approaches to opportunities for practical use of values and dynamics of changes taking place in society. University education should be aimed primarily at teaching a student how to solve practical problems rather than simply transferring knowledge. Russian universities are now undergoing changes that will lead to a new type of university. Previously, universities were focused only on multiplying knowledge, today the commercialization of developments becomes important. In the third generation universities, the development and commercialization of know-how and the capitalization of knowledge is the first role. This raises issues such as intellectual property protection. We attract new knowledge, new skills. University 3.0 is primarily an open university that actively cooperates with industrial companies and foreign counterparts. Interaction with industry has a positive impact on the education process: students understand what disciplines they need for successful work, and accordingly build their education. The professor stressed that students should be responsible for their education themselves - to be able to choose the courses they consider necessary. When students have access to different companies, they get an idea of what disciplines they need. They are themselves responsible for education. When responsibility is shifted to students, then it motivates them to develop. The role of universities of the future to develop students. The goal of the university is to teach the student how to solve problems and capitalize knowledge.

\section{Integration of the University into the Regional Environment by Partnership with Business and Industry}

Universities should become a trend of changes in the region and support technological and industrial development with intensive interaction and participation with agents of the regional environment, according to the road map of regional development.

With the rapid development of technology, there is a need for life-long education, the possibilities of which are defined by the latest means of telecommunications (e-learning) and a variety of choices, not limited, to a certain extent, even by state borders. The need to learn and organize huge flows of information requires learning skills. The ability to learn, becomes a guarantee of social inclusion in the life of the region and to be in demand. Otherwise, a person risks being in a state of systematic lag.

Turning to digital education strategies is largely driven by the need to intensify economic development. The need to respond adequately to the growing volume of information, the development of high technologies and the new format of human-environmental relations determines the focus of education on the digital model. The modern educational system faces the challenges of overcoming the fragmentation of a narrow disciplinary perception of reality, a one-sided pragmatic focus on result and a orientation towards unity. A holistic theoretical and pragmatic education system is required. Trans - disciplinary paradigm, acting as the basis of synthesis of knowledge of man, nature, society and production, complements scientific rationality. It allows to create digital twins of production process of production of products and technological process of equipment operation. Create digital twins by training neural network systems based on accumulated big data related to manufacturing for intelligent process and equipment management. Control the digital twin either in consultation mode, automatically or by parameter adjustment. Intelligent management of production by digital twins optimizes its operation, increases productivity and competitiveness of products according to quality and price.

The development of human capital as the main resource of the country and a key factor in the development of the modern economy tends to increase life expectancy and healthy life. Now it is about extending healthy life activity for 30-40 years, and the new bar, will become 80 years. Transferring the population to a healthy lifestyle will solve this problem [13-15]. To do this, the university needs to provide: acquisition of knowledge of competences on healthy lifestyle; the formation of a social culture of a healthy lifestyle.

\section{Platform Solutions for Integration of the University with the External Environment}

The infrastructure of the external environment includes energy, engineering networks, electricity and water supply, transport, telecommunications, cybersecurity, finance, food system, digital health care, public administration and other life support areas of any region.

In the areas of life support, a large amount of data is accumulated, on the basis of which decisions are made with the help of a certain algorithm without the participation of a person and any intermediaries. Such a system is called a digital platform.

The introduction of innovative digital and engineering solutions will increase the efficiency of urban management, and Russian cities will become more comfortable for life. Using smart platform solutions in different spheres of urban life will increase the level of security, reduce costs for management and housing and utilities, improve ecology and transport accessibility, smart cities will become attractive for investors. According to the results of the McKinsey study, the introduction of smart cities technologies gives an increase of $10-30 \%$ to different parameters of quality of life in the city. 
Universities can take an active part in the development and creation of platform solutions for economic and social sectors of the regions, including: human capital development, technological entrepreneurship, infrastructure for enterprise development, digital technologies in urban planning activities, digital economy of the university, transport systems "Smart City," environmental improvement, telecommunications of the city of the future, digital platform of interaction of the university with the external environment, smart student campus.

Communication is becoming increasingly intelligent, digital and flexible. Initiatives such as Germany 's fourth industrial, the US industrial Internet and China 's industrial manufacturing show how the digital industry is transforming university education and training. At the current stage, it is important to create an open international technological platform for forming a broad coalition of universities of different countries in training and developing transdisciplinary research.

Universities can participate in the development of a humane global high-tech society [16-18].

\section{Conclusion}

In solving the complex socio-economic problems of society, and in organizing and conducting scientific research, universities have widely adopted a trans-disciplinary approach in the formation of an ecosystem of interaction with industrial and social instruments. The whole management system at universities should focus on supporting transdectoral innovative research. Creative transdectoral innovative transformative learning ecosystem contributes to the formation of humane technological society. The person makes good deeds, fully discloses creative and innovative abilities. Society builds the smart cities and houses, keeps nature ecology, reaches uniform prosperity, establishes laws the eradicating defects and the spreading virtues. New knowledge of a creative innovative ecosystem of education improves practical skills of citizens on improvement of quality of life. Humane society becomes intellectual and nature technological.

\section{References}

[1] Evgeniy Bryndin. Creative Innovative Higher Education of Researchers with Flexible Skills and Synergy of Cooperation. Scientific Journal of Research and Review, Vol. 1, Issue 2. 2018. P. 1-5.

[2] Evgeniy Bryndin. System Synergetic Formation of Society 5.0 for Development of Vital Spaces on Basis of Ecological Economic and Social Programs. I Annals of Ecology and Environmental Science. Volume 2, Issue 4, 2018, Page No: 1219.

[3] Evgeniy Bryndin. Technological, Economic and Social Aspects of Management by Development of the Digital Industry 4.0. International Journal of Managerial Studies and Research (IJMSR), vol 6, no. 4, 2018, pp. 19-30.
[4] Evgeniy Bryndin. Communicative Associative Logic of Cognitive Professional Robot with Imitative Thinking. Journal Engineering Mathematics, Volume 2, Issue 2. 2018. Pages: $79-85$.

[5] Evgeniy Bryndin. Directions of Development of Industry 4.0, Digital Technology and Social Economy. American Journal of Information Science and Technology. V 2, Issue 1. 2018. P. 917.

[6] Evgeniy Bryndin. Digital technologies of the industry 4.0. / Chepter 10, C. 201-222, Book: Computer Science Advances: Research and Applications. Nova Science Publisher. 2019. $252 \mathrm{p}$.

[7] Evgeniy G. Bryndin. Modeling of Transformation of Nanostructures by Cognitive Systems on the Basis of Big Smart Data. International Journal of Artificial Intelligence and Mechatronics. Volume 7, Issue 4. 2019. P. 19-22.

[8] Evgeniy Bryndin. System retraining to professional competences of cognitive robots on basis of communicative associative logic of technological thinking. International Robotics Automation Journal. 2019; 5 (3): 112-119.

[9] Evgeniy Bryndin. Human Digital Doubles with Technological Cognitive Thinking and Adaptive Behaviour. Software Engineering, Volume 7, Issue 1, 2019. P. 1-9.

[10] Evgeniy Bryndin. Mainstreaming technological development of industrial production based on artificial intelligence. COJ Technical \& Scientific Research, 2 (3). 2019. Pages: 1-5.

[11] Evgeniy Bryndin. Robots with Artificial Intelligence and Spectroscopic Sight in Hi-Tech Labor Market. International Journal of Systems Science and Applied Mathematic, V. 4, №3, 2019. P: 31-37.

[12] Evgeniy Bryndin. Formation of Technological Cognitive Reason with Artificial Intelligence in Virtual Space. Britain International of Exact Sciences Journal, Volume 2, Issue 2, May 2020. Page: 450-461.

[13] Evgeniy Bryndin, Irina Bryndina. Supporting Technology of Vigorous Activity by Normalization of Biofield and by Healthy Lifestyle. International Journal of Healthcare and Medical Sciences, 2019, Vol. 5, Issue 2. Pages: 1-11.

[14] Evgeniy Bryndin, Irina Bryndina. Technological Diagnostics of Human Condition According to Spectral Analysis of Biofield. Advances in Bioscience and Bioengineering. Volume 7, Issue 3, 2019. Pages: 64-68.

[15] Bryndin E, Bryndina I. Training of Healthy Lifestyle in Educational Schools. Asclepius Medical Case Reports 2019; 2 (1): $1-3$

[16] Evgeniy Bryndin. Creative innovative transformational ecosystem of formation of humane technological society. International Robotics Automation Journal. 2019; 5 (3): 9194.

[17] Evgeniy Bryndin. Transformation Modeling of Nanostructures by Cognitive Systems according to Big Smart Data. Chepter 3, Pages: 21-28. / Book "New Materials: Preparation, Properties and Applications in the Aspect of Nanotechnology". USA: Nova Science Publisher. 2020. 250 p.

[18] Evgeniy Bryndin. Development of Artificial Intelligence by Ensembles of Virtual Agents on Technological Platforms. COJ Technical \& Scientific Research. 2 (4). 2020. Pages: 1-8. 